\title{
Is it 'Augmented Reality'? Contesting Boundary Work over the Definitions and Organizing Visions for an Emerging Technology Across Field-Configuring Events
}

\author{
Tony Liao* \\ Assistant Professor \\ Department of Communication \\ University of Cincinnati \\ Cincinnati, $\mathrm{OH} 45220$ \\ Phone: +13109093509
}

*Corresponding author \& reprint requests

This article was supported by grants from the National Science Foundation Science Technology and Society Division [Award \#1330297] and Cornell's Institute for the Social Sciences. 


\begin{abstract}
In recent years there has been growing recognition that Field-Configuring Events (FCEs) play an important role in connecting stakeholders, conferring authority to certain members, and shaping the organizing visions surrounding emerging technologies. While much of this work has examined the features of FCEs, the implications and outcomes of FCEs, and the coalescence of FCEs, this study contributes to our understanding of fields that are not converging, rather different stakeholders are actively creating and summoning new FCEs to assert authority. This case also examines the relationship between definitions and organizing visions, as the discursive and social contexts in which these boundaries are being contested. This study follows the emerging interorganizational augmented reality (AR) community, as a group that unites under the term AR but has been continually negotiating its meaning for decades. Through extensive participant observation at numerous global conferences and indepth interviews, this study shows how various definitions originated and evolved, how new emerging artifacts have challenged definitions, how specific groups have coalesced around definitions, and the various ways that they are organizing at and across FCEs to contest these definitions. These findings of how discourse flows across FCEs contribute to our empirical understanding of the tactics that various actors engage in to draw symbolic, social, and material boundaries around a field, as well as how these debates and commitments ultimately shape the participants in the community and subsequent work that comes out of the community.
\end{abstract}




\section{Introduction}

Emerging technologies are the result of complex social, technical, and organizational negotiations (Abbate, 2000; Bazerman, 1999; Bijker, 1995; Marvin, 1988; Swanson \& Ramiller, 1997). In the earliest stages of emergence, they exist as a combination of ideas, blueprints, prototypes, and promises, often surrounded by speculation and speculators hoping to push the technology forward (Brown, Rappert, \& Webster, 2000; Flichy, 2007). They are difficult objects to understand, however, given that the space is characterized by frequent unverifiable claims about technologies that have yet to materialize (Callon, 1986; Garud, 2008; Fortun, 2008; Hedgecoe \& Martin, 2003), entrepreneurial moves toward commercial implementation amidst changing economic conditions (Freeman \& Soete, 1997), and problems of political legitimacy (Brown, Rappert, \& Webster, 2000; van Lente \& Rip, 1998). Often, these communities form around an organizing vision, defined as "a focal community idea for the application of information technology in organizations (Swanson \& Ramiller, 1997; p. 460).”

The question of how communities circulate organizing visions and how these visions become dominant, however, is a complicated issue. One feature that is increasingly prevalent among emerging technology fields is the importance of 'Field-Configuring Events' (FCEs), or "temporary social organizations $[\ldots]$ in which people from diverse organizations and with diverse purposes assemble periodically, or on a one-time basis" (Lampel \& Meyer, 2008; p. 1026). These conference spaces are not independent organizations, but are places where a heterogeneous set of actors gather that "make it possible for streams of events to intersect, amplifying certain dynamics while dampening others" (Garud, 2008; p. 1084).

While there is increasing recognition that FCEs can effectively connect individual and organizational actors (Anand \& Watson, 2004; Garud, 2008; Glynn, 2008), forge collective beliefs (Zilber, 2007), and confer formal authority to members (Meyer, Gaba, \& Colwell, 2005; Lampel \& Meyer, 2008), the long-term consequences of these FCEs (both planned and unplanned) are still being explored (Garud, 2008; Lampel \& Meyer, 2008; McInerney, 2008). Several empirical pieces have examined single FCE (Hardy \& Maguire, 2010; Oliver \& Montgomery, 2008), and found a wide range of 
institutional actors, discourses, and interests. More recent work has looked into how the confluence of multiple FCEs form field level multiplicity (Zilber, 2011) and shape transnational policy (Schüßler, Rüling, \& Wittneben, 2014), with a recognition that more work needs to be done to understand internegotiations between multiple FCEs that are formed across a number of organizational and disciplinary arenas and longitudinally over many years.

This study examines a broad community of multinational actors and organizations that are working on augmented reality (AR) technologies. The term 'augmented reality' was coined in the early 1990's by Boeing engineers Caudell and Mizell (1992), but more than 20 years after its conception the significance of the label 'augmented reality' is broader than the origins and lies in how it got adopted by a group of people to describe and define their work and activities. In the early years it was a small but steadily growing group of academics working on AR, who gathered at academic workshops and conferences. Later, as developments in mobile smartphone technology made it technologically possible to look through a mobile device and overlay virtual graphics on the space, new commercial and industry stakeholders emerged.

The AR community is a collection of disparate industries, experts, and authorities, with different actors hoping that it might change people's perception of physical place (Liao \& Humphreys, 2014), become a tool to aid medical procedures (Sielhorst, Feuerstein, \& Navab, 2008), be useful for maintenance and repair (Henderson \& Feiner, 2009), become a way to animate news stories (Pavlik \& Bridges, 2013), and serve as a platform for delivering advertising content (Liao, 2015). Given these disparate focuses, this case provides a unique opportunity to study a community that has united under the domain of AR and held FCEs for many years. As they are becoming a burgeoning industry there have been important tensions around the definition of the term AR, all while simultaneously creating the artifacts that enable its existence and industrial/commercial success. This study analyzes the time period where a new set of stakeholders and FCEs formed, and the evolution of various groups and tangible strategies they took to advance and preserve organizing visions and goals that were often at odds with one another. 
This study, which has followed the AR community at these events for several years, builds on existing organizational theories and FCE literature to examine 1) the ways that conflict occurs at and between FCEs across time, 2) how a series of FCEs are created in relation to (and sometimes in opposition) to one another, and 3) the ways that FCEs may be preconfigured around certain boundaries and how people at these events enact boundary work. This paper will first build on literatures from science and technology studies, information science, and organizational science, then draw on these theories to analyze the case.

\section{Futures Discourses, Organizing Visions, and FCEs}

The concept of discursive futures as a lens for understanding innovation has been an important one in both organizational literature as well as science and technology studies, given that innovation is an inherently future-oriented enterprise with people working to create new understandings, possibilities, and artifacts (Brown, Rappert, \& Webster, 2000; Flichy, 2007). The relationship between discourse and technology has been examined in terms of metaphors about technology (Wyatt, 2004), the champions who promise the technology (Van Lente \& Rip, 1998), and the strategic decisions to engage in certain discourses (Barrett, Heracleous, \& Walsham, 2013). A growing body of literature has examined the power of future visions, expectations, and promises that people advance about new scientific and technological fields and how futures discourse can influence the subsequent trajectory, materiality, and perception of an emerging field (Brown, Rappert, \& Webster, 2000; Borup et al., 2006, Fortun, 2008; Hedgecoe \& Martin, 2003; Pollock \& Williams, 2010; van Lente \& Rip, 1998). In studying the social processes of innovation, van Lente and Rip (1998) conclude that future representations and promises are "as important as the actual production of artefacts and validation of knowledge claims (p. 245)."

The role of futures in information technology innovation is recognized in Swanson and Ramiller's (1997) model for understanding innovation processes (figure 1), which theorizes that there is a mutually constitutive relationship between the different stakeholders trying to bring together a community and the organizing vision they rally behind. The organizing vision plays an important role in attracting and constituting the community participants, shaping the practitioner subculture, emphasizing business 
and technical problematics, and driving the adoption of a technology (Swanson \& Ramiller, 1997). The process of settling on an organizing vision is essential to understanding an emerging technology, because how the organizing vision gets interpreted, legitimized, and mobilized has implications for its adoption and diffusion (Currie, 2004). While much of the work looking at organizing visions has focused on its role in the adoption and diffusion of innovations (Ramiller \& Swanson 2003) and the eventual forgetting of the organizing vision (Grint \& Willcocks, 1995; Ramiller \& Swanson, 2003), less empirical work has examined the actual negotiation over the discourse and creation of the organizing vision, the places where negotiations occur, and the various motivations and power disparities between these groups.

Swanson and Ramiller (2004) note that through individual and organizational actions organizing visions can evolve over time, "marked by rising and falling visibility, prominence, and influence over time" (p. 557). One important question that scholars have asked of the model is about how this ebb and flow of organizing visions occurs, or "why [...] some visions become highly popular and generate voluminous discourse, while others do not?" (Wang, 2008; p. 24). Quantitative attempts to examine the shift from one discourse to another looked at terminology in articles to assess the ascendancy and descendancy of certain organizing visions (Wang, 2008), but still more work is necessary to explain and understand not only why these disputes over organizing visions take place, but also how the actors engage in certain practices and bring resources to bear to solidify and enforce their visions.

Linking FCEs to Swanson and Ramiller's $(1997,2004)$ organizing vision framework is useful first as a practical matter, given that emerging technology fields are increasingly shaped at FCEs, as a set of forums where political and social negotiations take place (Garud, 2008; Lampel \& Meyer, 2008; Zilber, 2011). Second, while both concepts recognize the importance of community discourse in driving forward the technological innovation, FCEs elevate the places where discourse converges and are "likely to generate multiple discursive spaces (Hardy \& Maguire, 2010; p. 1367).” Third, whereas the organizing vision framework focused more on its role in mobilizing resources, analyzing FCEs as the place where organizing visions are contested allows us to more explicitly address the role of power in configuring the space and the ways that coalitions can fragment in setting/contesting organizing visions. 
This study also builds on our understanding of FCEs in terms of not only how a multiplicity of actors come together (Garud, 2008; Zilber, 2007), but also how different configurations of stakeholders gain power and create new FCEs to advance their position. While one of the key features of FCEs is that they afford actors in less prominent positions the platform to influence the field (Hardy \& McGuire, 2010), we do not know how exactly that process happens within and across FCEs, as well as how organizing visions get maintained and contested across the field. Zilber (2011) in particular has called for more work in understanding the long term maintenance and social contestation across FCEs: "[Existing studies] mainly documented fields that converged into a homogenous design. We still lack an understanding of the dynamics of FCEs in fields characterized by multiplicity (p. 1553).” This case study examines a contested field with multiple stakeholders and the overlap, intersection, and presentations at their respective FCEs. To do this, I turn specifically to literature about definitions and boundary work to explain how various FCEs are structured and configured to contest the organizing vision surrounding the technology.

\subsection{The Importance of Definitions}

Defining and categorizing are recognized in information and organization science as an incredibly difficult task, one that is fluid and constantly being enacted with tremendous implications. Definitions at the most fundamental level describe what something is, but within that simple act there are important values and politics enacted in the work of determining the criteria for a particular definition and deciding what fits within those definitional limits (Bowker \& Star, 1999; Busch, 2011). With emerging information technologies and services, the act of defining and deploying terminology is especially critical, because it becomes a way of grouping similar applications, services, and technologies, allow entities to differentiate products from their rivals (Swanson \& Ramiller, 1997), claim specific areas of knowledge and expertise (Suddaby \& Greenwood, 2001), and present the technology as popular, innovative, and beneficial (Wang, 2009). Oftentimes, these names are abstractions, referring "not to a specific homogenous product but to a more or less heterogeneous collection of artefacts (software, management techniques) which then went onto link a community (or, rather, several overlapping communities) of suppliers, intermediaries, and 
adopters (Pollock \& Williams, 2011, p. 195).” Uniting under a technological field, then, requires engaging in debates and discussions over the definition of that field. Along with this comes critical questions, such as who gets to decide what the terms are, what is contained within them, and how they get picked up and gain meaning within the community (Pollock \& Williams, 2011). Sometimes it may be outside entities or professional marketing firms creating terminology and categories (Pollock \& Williams, 2010). Other times buzzwords are shaped by a stakeholder community around an organizing vision (Swanson \& Ramiller, 1997), or strategically chosen to appeal to different corporate and political actors (Barrett, Heracleous, \& Walsham, 2013). Once enacted, definitions can be used to define "content and basic assumptions of what dialogues are permitted as well as who is invited to participate" (Prince, Barrett, \& Oborn, 2014; p. 124).

While it is common to see linear histories of AR development that list these definitions before moving on to the devices and problems (van Krevelen \& Poelman, 2010), these overlook the context and goals of those particular definitions as well as what actors are taking up different definitional criteria (both old and new) to rigorously enact a vision of AR. Therefore, understanding how and why various groups are contesting the definition and authority of certain actors is an increasingly important concept for understanding emerging technologies (Pollock \& Williams, 2011).

\subsection{Boundary Work Across FCEs}

While both Swanson \& Ramiller's framework (1997) and FCEs literature recognize the role of power and conflict in negotiations, often these disagreements are theorized on a case-by-case basis, specific to the individuals that capitalized on certain forces (see McInerney, 2008). This study broadens our understanding of individual actions at FCEs by theorizing them as larger boundary conflicts, where people from disparate disciplines and professions engage in 'boundary work.' (Gieryn, 1983; 1999). 'Boundary work' is the process of distinguishing and consolidating amongst fields, and represents an important resource that translates into practical action as well as an important means of social control and sanction within the community (Gieryn, 1999). Boundary work can take place amongst any set of actor groups that attempt to claim authority, highlighted by three specific ways that stakeholder groups may act: 
1) to expand authority into domains claimed by other professions, 2) to monopolize professional authority and resources to exclude rivals, and 3) to protect the autonomy over professional activities by placing the blame on outsiders. Boundary work can happen within fields, or across fields, and was first observed as the professionalization work that scientists engage in as to distinguish their work from 'non-scientists' (Gieryn, 1983). The work of science, in this instance computer science, demarcates boundaries and territories as a form of boundary work over who has the authority and expertise to speak for the domain (Gieryn, 1983; 1999).

Boundary work has been a useful concept for explaining how knowledge creation is social, and has been a key concept for organizational and social science researchers (Zietsma \& Lawrence, 2010). One key type of boundary work is symbolic boundaries, defined as "conceptual distinctions made by social actors to categorize objects, people, practices (Lamont \& Molnár, 2002; p. 168).” Another is a social boundary, where widely agreed upon symbolic boundaries are objectified in unequal access to or unequal distribution of material and nonmaterial resources (Lamont, 1992). While early work has linked symbolic definitional boundaries to social boundaries (Bowker \& Star, 1999), more work is necessary in cataloguing the key mechanisms associated with the activation, maintenance, and disputing of boundaries (Lamont \& Molnár, 2002).

Studying multiple FCEs provides a useful site for understanding how in emerging technology fields, symbolic boundaries become social boundaries. FCEs are places where stakeholders that have an important stake in the technology gather, but they come together from different social worlds with partial jurisdiction over the resources of the technology (Star \& Griesemer, 1989). This is consistent with the interorganizational community that Swanson and Ramiller (1997) describe, but to their model we add an important feature - active contestation across stakeholders from various domains and fields of authority. These FCEs are comprised of groups that are not trying to coalesce around an organizing vision, rather they have different goals and motivations for pushing certain definitions and classification schemas, each with their own moral and ethical agendas that "valorizes some point of view and silences another" (Bowker \& Star, 1999, p.5). 
This study expands existing literature on boundary work by examining how symbolic boundaries (e.g. definitional disagreements) get activated and enforced in these material spaces. Building on theoretical work examining how boundaries recursively shape the practical work necessary for innovation (Zietsma \& Lawrence, 2010), FCEs becomes a useful lens for thinking about boundary work enactment, as material spaces where various stakeholders attempt to make their definitions dominant and socially enforced. It is also only across various FCEs where we can see how different actors respond to boundary work. Zilber (2011) found that even within a singular FCE the different constructions and narratives occur in different social spaces at the same event - this study aims to understand how these competing discourses move across FCEs, and how FCEs are configured to engage in and enforce boundary work. As people across FCEs have started to engage in boundary work contests over acceptable forms and forums of knowledge construction, this has important implications for shaping the material arrangements of these spaces and the practices of innovation related to who gets to be in the community, what the culture of the community should be, and the organizing visions and business problematics that are prioritized.

\section{Methods}

This article is based on over four years of fieldwork and participation observation in the AR community. Participant observation is particularly useful when the research examines interactions that take place in specific, physical locations (Lofland et al., 2006), and there were several of these FCEs that were created around $\mathrm{AR}$ - business conferences, standards meetings, and academic conferences. In tracking the AR industry, in the Fall of 2011 I started attending several meetings of a local AR group called Augmented Reality New York (ARNY). From there I was directed to the Augmented Reality Event in May 2012 (ARE2012), a conference geared toward the industry side of AR and the creation of a business market. I returned for the conference in 2013, which had been renamed Augmented World Expo (AWE2013) to reflect the international scope of AR and the spectacle of the conference. Later that summer I attended the AR Summit 2013 in London, billed as the preeminent European conference on AR. In the Fall I attended InsideAR 2013 in Munich, one of the largest AR business conferences, described as 'where the AR industry meets.' I also attended Augmented World Expo New York in Spring 2014 
(AWENY 2014) and Augmented World Expo again in Spring 2015 (AWE2015). These were some of the largest and most prominent AR business conferences in the world.

During this time, I also attended AR standards meetings, where representatives from AR companies gathered to work on standardizing certain technical features. I attended the Open Geospatial Consortium (OGC) technical and planning committee meeting in Redlands, California, in January 2013. In February 2013, I attended the $9^{\text {th }}$ International AR Standards Community (IARSC) meeting in Barcelona, Spain, a two day event with speakers from many different standards setting organizations (SSOs) coming together. In May 2013 I attended the $10^{\text {th }}$ IARSC meeting at Columbia University, and in October of 2013 I went to another OGC technical and planning committee meeting in Frascati, Italy. The last standards conference I attended was in March 2014, the $11^{\text {th }}$ IARSC in Crystal City, Virginia. I was attending these conferences as a researcher, but also was serving on an AR glossary taskforce, a group responsible for defining terms in the community, which informs my findings. Lastly, I attended the preeminent academic conference for AR, the International Symposium on Mixed and Augmented Reality (ISMAR) in Atlanta, Georgia in November 2012 and again in Adelaide, Australia in October 2013. I also began to actively participate in these organizations. It was at these field sites I was able to observe and interact with the people who were in charge of making decisions about AR. In total I attended over 19 meetings and conferences in 10 different cities, spanning across 6 different countries.

Writing these interactions in field notes is particularly important in pinpointing the indigenous meanings and interactional processes underlying those events (Emerson, Fretz, \& Shaw, 1995). They also allowed me to see how conversations were recurring and shifting over time, as well as patterns within the domains of specific stakeholder groups. One key methodological strength of this extended participant observation is the length of time spent covering these FCEs, which allowed me to track the discussion around new technologies that were coming out to see how communities moved and adjusted to these new developments. Another strength is the diversity of FCEs I attended, where different stakeholders in the field were meeting and discussing the same issues but from different and occasionally oppositional perspectives. From these conferences I have over 300 pages of field notes, from observations of formal 
sessions and events to social settings and mixers, all of which document elements of the social practices, values, and artifacts of these conferences as well as the distinct "social spaces" where different discursive constructions take place (Zilber, 2011).

\subsection{In-Depth Interviews}

I supplemented these observations with follow-up interviews with key leaders of the AR community and speakers/organizers of these events. Between November of 2011 and June of 2014, I conducted semi-structured in-depth interviews with 48 members of the AR community and spoke to many more in informal face-to-face settings. I began my recruiting by contacting speakers who presented at ARE2012. Interviews were then obtained through a snowball sample by asking those speakers who they felt to be authorities on AR, and was also able to speak with several important organizers and founders of the FCEs that I was attending. The consent document ensured confidentiality, so I created a table of all the participants with their pseudonym, job description (without specific companies or schools mentioned), and their primary affiliation within the AR community (industry, academic, standards) (see Table 1). In total I interviewed 26 members working in the AR industry, 16 academic researchers of AR, and 6 members primarily working on AR standards. Each interview was audio-recorded on a digital recorder with the informant's permission. Interviews lasted between 30-150 minutes [M=65]. My questions centered around understanding how they defined AR, who they considered to be central to the community, future uses and applications for AR, what problems they felt were important to solve, and how they saw the technology developing.

\subsection{Data Analysis}

Fieldnotes and interviews were coded using the qualitative coding software Dedoose. The definitional issue was one that emerged iteratively from the data, where informants would often make a point of clarifying what they considered to be AR. Across the whole corpus of interviews, a first round of coding broadly coded any response segment that referenced the definitional debate into excerpts. From those excerpts, I began linking those specific responses to people from various stakeholder groups (academia, industry, and standards). I then wrote extensive memos narrating the various strategies and 
boundary work that different stakeholder groups in the AR space were engaging in to define and classify AR (Lofland et al., 2006). I used these memos to triangulate the order of events and how they perceived distinct time periods when certain definitional moves and debates were occurring.

To understand the explicit and implicit motivations behind those definitions, a second round of coding was done examining the visions of the future people had for AR, specifically looking at the use cases and scenarios they advanced for AR, what they believed to be the key challenges for AR, and where they believed the technology was headed. These were designed to understand the various organizing visions that actors had for the technology, within those I also coded for references to other stages of the innovative process: ways in which they adapted to the core technology, what they wanted to be the practitioner subculture, purported business problematics, and goals for adoption and diffusion (Swanson \& Ramiller, 1997). I then linked these organizing visions and characteristics to the specific definitions that the informants supported, creating a comparison between my two rounds of coding. From there I looked for patterns and similarities across definitions and future visions, until I reached a point of theoretical saturation, or where there were a finite number of clearly distinguished categories for definitions and organizing visions. These were then placed in chronological order to account for certain technological developments and definitional moves, which organize the findings and explain how and why certain members within each group were engaging in certain boundary work tactics and negotiations over the definition of AR.

\section{Phase 1: Establishing Independent FCEs through Definition}

Shortly after the term AR was coined, an early group of academics moved to solidify it as a field of inquiry. Milgram and Kishino (1994) offer one of the first definitions of AR, in their 'virtuality continuum,' which places reality on one end of the spectrum and virtual reality on the other end. In between the poles are two ways of thinking about mixed reality, one of which is 'augmented reality' defined as a mostly real physical environment with virtual objects overlaying the scene (see figure 2).

This definition was an important step toward defining AR as a mutually exclusive subset of virtual reality (where VR refers to $100 \%$ virtual environments). Moving away from VR was the first 
boundary move to establish academic independence and creating their own field. The historical context in which this type of move occurred was also important. Fred, a professor of computer science who has been working in the field for decades, explains:

VR was becoming academically respectable in the early 90's. [...] However, shortly after that there was a big rush into commercial VR, some of it due to overhype by researchers and a number of companies that invested heavily in VR. The technology wasn't ready and some really subpar products were pushed out to meet a quarterly business cycle. People did not accept it, development slowed, and [...] it no longer felt like it was cool to work on or the next big thing. [...] Soon many researchers turned to AR to strategically move away from VR, and it was being done by enough people that there could be a symposium workshop and a conference in the late 90's (interview).

This quote tells us about the motivation and perspective of AR researchers who wanted to distance themselves from VR, utilizing Milgram's definition to clarify its independence and monopolize resources. The workshop Fred was referring to was called the 'International Workshop on Augmented Reality' (IWAR 1998), the first of a series of academic FCEs which explicitly carved out its boundaries to exclude VR work and other related disciplines so they could meet without the 'overhead' of other events. This workshop would eventually become an annual conference, later renamed the 'International Symposium on Mixed and Augmented Reality' (ISMAR), a direct recognition of Milgram's mixed reality spectrum. This move away from VR is still socially enforced amongst longtime members and newcomers. At a student poster presentation at ISMAR2012, a longstanding member questioned the presenter: "where is the AR in this? Why isn't this just VR?" Whether something is 'just VR' is an a priori question that academics hoping to enter the community must justify, to preserve their status as a special subset of the mixed reality spectrum. Liu, another professor of computer science puts it succinctly: "you can publish AR research at VR conferences, but you can't publish VR research at AR conferences (ISMAR 2013)." In the first phase, the academic community was utilizing the definition as an original boundary move to move away from a preexisting field, while also building up a group of people to work on their organizing vision.

\subsection{Organizing FCEs through Definitional Criteria}


While the mixed reality spectrum was useful in drawing the boundaries in relation to VR, it was limited in its actual definition of AR: "we take the term to refer to any case in which an otherwise real environment is "augmented" by means of virtual (computer graphic)." (Milgram \& Kishino, 1994, p. 4). It was more a definition of exclusion (not VR) as opposed to a clear criterion for what constitutes AR. In an effort to clarify criteria, Azuma (1997) defined AR as: "systems that have the following three characteristics: 1) Combines real and virtual 2) Interactive in real time 3) Registered in 3-D” (p. 356). This became the operative definition for the early AR community, along with the initial visions and use cases for AR outlined in the original piece: medical applications, maintenance and repair, annotation and visualization, robot path planning, entertainment, and military aircraft (Azuma, 1997). By one metric, Google scholar lists over 5500 citations of Azuma's paper. Seth, one of the members of the steering committee, explained that this definition was how they thought about organizing the academic FCEs: "the shadowy hand behind ISMAR, the steering committee, have been basing our definition of AR on Azuma's dissertation for years (ISMAR 2013).”

Participants report that the criteria have effectively become a membership negotiation requirement to enter the community. One example comes from Brian, a computer science professor who presented at both ISMAR2012 and 2013, and how he was confronted by this definition in the peer review process: "If you look at Azuma's classic definition as visual, 3-D, real-time. One of the comments I got back was 'is this really AR because when you look at the [application] interface it's a 2-dimensional representation.' There was some debate about 'Is it AR?', so I had to make the case in my rebuttal." This definition was simultaneously an attempt to expand their authority and stake a claim to a new space, while also serving as a form of membership negotiation. Over time, this eventually becomes hardened into ways of self-structuring as both leaders and members adhere to and enforce these criteria. Azuma became a member of the ISMAR steering committee. A ten year content analysis of the work coming out of ISMAR found that much of the published work focused on specific issues related to tracking, registration, and calibration, which work to create AR experiences as defined by Azuma (Zhou, Duh, \& Billinghurst, 2008). 
As the earliest actors in the space they had the exclusive authority to do this, because they were the primary actors at the time, and they created their own forums and enforced the definitions there to guide work in the academic domain for over a decade. Through peer review and social norms, the definition became an 'obligatory point of passage' that Callon (1986) highlights, a process that actors make necessary to consolidate alliances. These determinations also socialize new actors into the community, as the borders get placed and policed, 'scientists' learn where they may not roam without transgressing the boundaries of legitimacy, and 'science' displays its ability to maintain monopoly over preferred forms of conduct (Gieryn, 1999, p. 16). This demonstrates the power that definitions have in configuring FCEs, which over time enforces boundaries around the technology, focuses the scope of work, and determines what work gets valued in those forums.

\section{Phase 2: Disputes in Clarifying and Applying the Criteria}

The question of how to apply these criteria to real world examples and applications, however, gave rise to a number of different interpretations of the criteria. One example of this was the debate over the $1^{\text {st }}$ and Ten system, which shows virtual lines on a televised broadcast of American Football (see Figure 3). First introduced in 1998 and widely adopted for football broadcasts in the 2000 's, the $1^{\text {st }}$ and Ten system was one of the first applications that gained widespread public recognition as associated with $\mathrm{AR}$, as popular press depictions often reported it as such:

That yellow first-down line shown on televised football games isn't really on the field. But to viewers, it appears to be there, just like the turf and the players. The technology $[\ldots]$ is an early commercial example of a field of computer science called augmented reality (Berlin, 2009).

The company that manages this technology is called Sportvision, and they are happy to make the association with AR. Morton, an executive at Sportvision, explained:

I got there just after they put AR on television. [...] I think the first set of impact has to do with providing augmented reality that naturally meshes with $[\ldots]$ understanding the game, understanding the rules of the games, understanding the progress of the game, and just basic enjoyment. [...] When I go and talk to another technology partner here, [...] we'll talk about AR explicitly and they have a very high level of awareness of [...] where it (AR) is right now (interview, emphasis added). 
This association with AR, however, is contested by some members of the AR community, and illustrates some of the differences in how Azuma's criteria are interpreted and applied at these conferences.

Some argue that it meets the first criteria - combine the real and the virtual - because the yellow line is virtually mixed with the reality of the football game. The result is a composite of virtual objects and the real environment. Other people argue that "real" has to be the actual matter that is in a users' physical reality (e.g. the field itself if someone were at the stadium). Because the $1^{\text {st }}$ and Ten system shows a televised representation of a field with graphics on top, they argue it does not combine 'real' and 'virtual.' Under this interpretation, for it to meet criteria 1, the user would need to be physically at the game using a device to see a first down marker. This lack of consensus illustrates the range of interpretations one might have for 'real,' and how that might include or exclude certain technologies as AR.

Azuma's second criterion stipulates that AR needs to be interactive. The example given by Azuma is that 3D films (e.g. Jurassic Park) do not qualify as AR because they are not interactive for the user. Also these graphical overlays are not interacting with the real world, rather they are projected out of the screen. This definition is one of exclusion, however, and is less clear on what something would need to be to constitute interactivity, and whether interactivity is a binary classification or exists on a continuum.

Once again, different interpretations were proffered. Riley, a professor of computer science who was one of the organizers of some of the earliest academic FCEs, argued that the 1st down line does not meet the criterion: "Ron [Azuma] (and I) mean interactive for the person for whom the experience was designed for. $1^{\text {st }}$ and Ten is aimed at the viewers of the event. The consumer of the event has zero control over it. It's not "interactive" by any rational definition of interactive." Here is a user-centric definition, one that makes an appeal to the author's intent of the definition and argues that the augmentation has to react to the user input (see figure 4). The argument is that like a $3 \mathrm{D}$ movie, users do not control the $1^{\text {st }}$ and Ten system. 
Others challenged this interpretation, arguing that it should not be about the user. The fact that the system produces virtual objects that react to the physical environment should be sufficient to meet the condition of interactivity. With the $1^{\text {st }}$ and Ten system, the lines are programmed to react to players' bodies that cross the line so as not to occlude live action, so they argue that it is 'interactive' with the real world. Here is a different interpretation of interactivity that happens between the system level and the environment, not at the user level (see figure 5). Further, they argue that the $1^{\text {st }}$ and Ten system is able to change camera angles, respond to instructions, thus meeting the user interactivity criteria for the operator of the $1^{\text {st }}$ and Ten system.

Some argue that a source-based interpretation is better because user interactivity is subjective. They question how much user interactivity is 'enough,' and whether simply activating the experience would count as interactivity. Others argue via hypotheticals, pointing out that people are passive viewers of the $1^{\text {st }}$ and Ten experience not by choice, but by the limitations of the television medium. If people could someday manipulate their own television viewpoints of the $1^{\text {st }}$ and Ten display, then the system would meet the user interactivity criterion. Each of these interpretations of interactivity further demonstrates the ambiguity of applying the criteria, as well as ways in which people could draw limits around a range of technologies (real and hypothetical, current and future) that would/should be classified as AR.

Azuma's criteria also stipulates that AR has to be 'real-time,' which becomes another point of contention given that 'real-time' is a construct of computing that refers to the speed of calculations. Because any computation of graphics will have an asymptotic relationship to the actual passage of time, the question is in fact always 'to what degree' constitutes 'real-time.' Supporters of the 1st and Ten system argue that it meets the real-time criteria, because there is no perceivable delay in the augmentation given that it adjusts to events happening on the field (e.g. players/objects moving over the line). Boris, a leader in the standards community, advances this interpretation of real-time as 'without perceivable delay,' which makes it a user-centric question and dependent on the limits of human perception. Riley disagreed, arguing that the first down line is not real-time in that it is delayed from the events as they 
happen: the television broadcast is slightly delayed so the augmentation can be placed atop it. He argued that because it could be viewed days later without any change in the experience, it is not real-time. This interpretation argues that real-time should be a source-based criterion, and concludes that independent of perception, the computing has to be instantaneously linked to real world events, as they are happening in order to be AR.

What $1^{\text {st }}$ and Ten reveals is that even amongst academic community members who rely on Azuma's definition, there is a level of indeterminacy and sub-factions that have different interpretations for what the criteria means. The rigor with which these tests are applied is also up for debate, which often stem from their broader goals for the technology. In the $1^{\text {st }}$ and Ten system example, some members did not mind adopting a particular interpretation to have AR associated with what is a popular and wellexecuted application. For them, not meeting each prong of Azuma's criteria is not a reason to exclude it outright; rather the system is in its current form a close approximation and some of those criteria might be met with future developments. Other members argue that irrespective of popularity, the failure to meet any one prong of Azuma's criteria (however one chooses to define that) is sufficient to reject it, because Azuma states that the systems must possess all three characteristics. While these interpretations demonstrate that definitions are always a matter of applying social standards, even these disagreements within the academic FCEs serve to cement Azuma's definition as the criteria with which the debate should occur.

\section{Phase 3 - New Stakeholders Broadening the Definition, New FCEs}

While the adoption of Azuma's definition and criteria for AR was motivated by a move away from VR, that definition was primarily enacted, enforced, and disputed by academics at their own FCEs. The $1^{\text {st }}$ and Ten system was also a very specific sports application, and did not intersect much with the work of the academic forum. In 2009-2010, however, when several companies like Layar, Metaio, and Wikitude announced that they were offering location based 'AR' browser applications on smartphone devices, it represented a significant step in bringing AR out of the laboratory and into everyday users' hands. One of the founders of one of the first industry focused conferences, Augmented Reality Event 
(later renamed Augmented World Expo), Aaron, actually first got interested by attending an ISMAR conference, and became motivated to create a separate FCE specifically for businesses. In the years that followed, a number of new companies were encouraged by the possibilities for public AR use, and started creating meetups around AR that eventually turned into large business FCEs to cater to the business/commercial side of AR (e.g. ARE, AWE, Augmented Summit, InsideAR, etc.). This brought a wider set of actors to the community, who had their own authority to create new forums and move the AR discussion into their domains of interest.

The location based mobile browser companies brought with them millions of dollars in venture capital money, and were beginning to gain publicity and release publicly available applications and content. The arrival of these location based AR browsers even sparked a debate at the academic FCEs that had previously relied on Azuma, to gravitate toward broader definitions. Greta, a professor and former committee chair of ISMAR, argues that these real world developments should cause them to move toward a broader definition:

One thing that has happened [...] is through consumer devices, through iPhone, camera, GPS, devices that what would house AR experiences. [...] When technologies become more widely used, when that happens the definition of AR always changes (interview).

Stan, also a professor, proposed broadening the definition of AR to 'any context-aware or location-based computing experience that overlays content on the physical environment (interview).' Echoing Greta's argument, he believes that applications like mobile AR browsers represent a significant breakthrough in technology but are too often excluded for technical or arbitrary applications of criteria. Rather than arguing about criteria over degrees (e.g. what is sufficiently real-time, interactive), he argues that the ability to overlay virtual graphics on top of a physical location specific to the user should be sufficient.

\subsection{Embracing a Colloquial Definition?}

While the mobile browser/application companies were pushing to extend the AR definition to include location based browsers, other business newcomers wanted to disregard definitions altogether. Many of these business actors were new to AR, and had little to no commitment to the previous definitions. At each of the industry centered FCEs I attended, a common theme was that they have grown 
tired of justifying their presence in the AR community. They felt that they were the ones making significant financial and material commitments for the advancement of the technology; and that it is a counterproductive exercise for the community to apply 'a priori' criteria about the source of the augmentation and the conditions under which it is produced to assess whether something should 'count.' They also worry that getting bogged down in these debates ignores real world applications and confuses the public about the term AR. A new potential user who heard the academic debate over $1^{\text {st }}$ and Ten may not understand or care what the criteria is, prompting industry actors to pejoratively mock the definitional debate as an 'academic question,' both in reference to the people having the debate and the practical value of it. Josephine, a marketing manager from a mobile AR company explains:

We need to stop debating about the jargon and definition of AR and instead focus on the experience and how it will help people get through their day. We need to take it back to $[\ldots]$ how it will allow people to digitize things they couldn't engage with before and allow people to $[\ldots]$ discover content (interview).

Amongst some industry actors, the simplest approach would be to take a colloquial approach to defining $\mathrm{AR}$, not as a set of academic criteria but by simply combining the definition of 'augment' and 'reality,' focusing on the user perspective and perception of computer graphics. Many of these are marketing directors who believe AR should be used not as a technological description, but instead as a branding and marketing term. Here is a recognition that there is value in the term based on its historical/cultural usage, but an effort to supplant the meaning of the term by using their power to release products and name/describe applications however they choose. In time, they hope to make a new de facto definition of AR, as more first-time users begin to associate their products with 'AR.' These represent instances where new business and marketing interests attempt to expand their authority into the scientific domain, to redefine and diminish the importance of academic definitions (Gieryn, 1999).

\section{Phase 4 - Competing Definitions, Visions, and Authority Across FCEs}

The difference between definitional perspectives is evident depending on the FCEs, and also becomes a place where distinctions and boundaries get drawn. There is some fear that the new stakeholder definitions run counter to the original motivations for defining AR, and more broadly to their 
longstanding practices and practitioner subculture. Many academics who were apathetic to these mobile AR browsers as entrants to the AR space started rallying around the Azuma criteria to oppose expanding the domain of AR. Here's Dennis, a Ph.D. student in a computer science research program:

A lot of things are being called augmented reality even though they're not. [...] Anything that's on the phones right now, because it has to feel like it is part of the world, in my opinion. Just having things hovering around, based on location but not the actual real world environment, that's not AR, because it's not interactive. It's just a nice little thing that you're putting there (interview).

One of the fears in broadening the definition is over the public association with AR as well as the types of futures that are emphasized: “I have all these browser apps on my phone, but I never use them. I just don’t need to use AR to find the Starbucks, that's just such a boring application of AR (Fred, interview).” Many academics fear that these mundane commercial mobile applications would turn people against the technology and detract from their organizing vision around AR for medical applications, maintenance and repair, and educational applications. A stronger response to these mobile applications was to advance a hierarchical distinction between "hard/strong AR" and "soft/weak AR." Here's one presenter trying to convince industry actors to make this distinction as a call to action:

There's been a lot of 'so-called augmented reality' on mobile devices over the past couple years, but most of it really sucks. Most of it is what I would call 'weak AR' based on the compass, GPS, and vague sense of how stuff out there in the world might relate to your device based on those rather crude sensors. 'Strong AR' is when [...] everything is stable and visual, that's 'strong AR'. Of course the technical requirements are so much greater (ARE2011)

Here, "hard/strong AR" refers to an idealized state of AR with sensors that understand the physical environment and with virtual displays that indistinguishably interact with elements of the real world (tightly registered graphics). Supporters of this 'hard AR' distinction and definition emphasize the desirability of head worn devices (HWD) of AR to further distinguish themselves from the mobile browser applications. "Soft/weak AR" refers to anything handheld, where the mixing of the real and virtual is imperfect (loosely registered graphics), and uses only geolocational data. This hierarchy grudgingly accepts mobile applications as AR, but expresses disdain for these early applications as merely temporary analogues. A number of academics began to add another criteria of 'tightness of 
registration' to the existing Azuma definition as a way of excluding mobile AR browsers, and by extension the consumer business problematics from the community. In terms of boundary work, the actors engaged in these discourses were using those terms to preserve an idealized form of AR as 'true AR' and segment out mobile browsers as 'so-called AR,' a discursive tactic to delegitimize challengers credibility akin to calling something 'pseudo-science' (Gieryn, 1983; Zietsma \& Lawrence, 2010).

\subsection{Standards Organizations as FCEs}

Business representatives from the location-based mobile AR browser companies strongly objected to the hard/soft AR dichotomy, arguing that this type of discourse has done the community a disservice by framing the issue in a dismissive, divisive way. It was here that certain companies began turning to standards organizations to mediate this definitional dispute, as well as actively shape standards to meet a broader definition. Standards setting is where organizations attempt to coordinate amongst multiple stakeholder groups and arrive at agreed upon conventions. Oftentimes the prerequisite to that is a standardizing of language and terms, which was first undertaken by members of the International AR Standards Community (which eventually became the AR Glossary Task Force). Given that many of the first members of the standards community were companies who were interested in mass market goals, their interests were reflected in the standard glossary. AR is defined not as a technology with a priori criteria, rather as an experience with certain common features from the users perspective. Augmented Reality Browsers and Geo-Spatial Augmented Reality were also defined, to reflect the broadening industry stakeholders. Led by Lester, the CTO of a major AR browser company, several AR browsers came together in 2011 to develop a formal technical standard called 'Augmented Reality Markup Language' (ARML 2.0), and formalize it through a standards setting organization called the Open Geospatial Consortium (OGC), a consortium that specializes in geo-location standards. By 2015, the OGC officially voted and approved ARML 2.0 as a formal standard, with many of the features of these mobile browsers codified under the term AR.

The move to standards demonstrates that these definitions are not just ideological battles, but are being linked to developmental outcomes. Mobile supporters are fighting back against the implicit 
machoism and elitism of the hard/soft dichotomy, arguing instead that a broader definition is necessary to change the current course and focus of AR development. These moves have even persuaded some academics that believe that the development of AR has been slowed by the rigid definitional gatekeeping, and will continue to stagnate if they do not broaden. Stan, one of the steering committee members of ISMAR, laments that: "the conference became a whole technocentric, academic wet blanket, if you will. As long as we're so academically oriented where we're focusing on these definitions, and registering virtual objects on physical places, [...] anything with ISMAR will be small and incremental (interview).” Across various FCEs, each instance of boundary expansion is met with subsequent boundary work defenses, but also realigns the space with occasional defections and calls to reexamine the original definition.

\subsection{Industry FCEs Move to Broaden Definition}

Industry actors also are utilizing their FCEs as a platform to advance the definition as well as solidify their organizing vision. For one, the futures emphasized at these conferences tended to focus on commercial purposes (advertising), outdoor uses of AR technology (e.g. tourism), and AR gaming. At Augmented World Expo 2013, the founders unveiled a new organizing vision, a consumer future where there would be "1 Billion active users of augmented reality by 2020.” By Augmented World Expo 2015, the definitional boundary between AR and VR was no longer enforced, as there was an entire exhibit sponsored by a VR company devoted to VR, as well as a number of panels and tracks devoted to VR hardware and issues.

The other place where industry actors have authority to change the definition lies in how the market is measured. As AR has started to become recognized as an emerging technological field, representatives from Forrester and $\mathrm{ABI}$ research are often at industry conferences presenting their market projections for AR. One of the market analysts who works on these reports explained that their conceptualization of AR is very broad: "My definition is rather simple. It's just essentially an Augmented Reality to build on the physical world with information supplemented in a number of contexts. (Justin, interview)." This is in effect another way of restating the colloquial definition, which allows companies 
and products that self-identify as AR to be included in the projections. This represents another area where the definitional battle could have been enforced, but thus far these actors have aligned with and tacitly accepted the colloquial definition over the academic one. By accepting the industry criteria that minimize technological distinctions in their mapping, the market projections are larger and the problematics focus primarily on marketing and advertising goals, which are then presented back to the audience at these industry FCEs.

\subsection{Reenforcing the Definition at ISMAR FCEs - 'If Everything is AR, Nothing Is'}

The strongest reaction amongst the academic community has been toward the colloquial definition advanced by industry actors. Several academics bristled at the attempt by industry actors to redefine AR colloquially as amorphous and lacking a clear line of demarcation. Brian, a professor of computer science, worries that this definition conflates other enabling technologies with AR:

A map that knows your current position is not augmented reality, it's not mediating your vision. Those virtual objects don't line up with the world in any meaningful way. A hearing aid is not augmented reality, all its doing is amplifying, it's not producing some virtual sound that interacts with reality in a meaningful way. [...] A system where you have a camera, you press a button, and it doesn't take a picture until something looks at you. That's automation, but it's not augmented reality (interview).

Within Brian's answer, we also see alternative language that he uses to categorize those other devices (e.g. amplification, automation), which further preserves AR as a unique category of research. In its ongoing forms, this rigorous control of language seen in certain parts of the AR community is a method of constructing an expert identity. These tacit community norms over what is 'not AR' develop over time and become a signifier that makes "correct technical language correctly used essential to the expert's claim to professional authority (Marvin, 1988, p. 46).”

Others like Riley make a slippery slope argument about the expansive potential of combining the meanings of 'augment' and 'reality':

The term 'augmented reality' is being pushed away from its academic meaning by a few different groups. [1] Those who are excited about the idea, and think whatever they happen to be doing is 'augmenting' 'reality' and thus they call it augmented reality. My issue with the 'phrase is defined by composing the definitions of the two words' is that it's meaningless. Coffee augments my reality ('I'M MORE AWAKE NOW!!'). LSD clearly augments my reality. Pollen augments my reality. Where do we stop? [2] Those 
who argue for a slightly broader definition, up to and including any 'context aware, or location based, computer experience' [...] [3] Those who have a business and want to benefit from the hype by calling whatever they do AR so they can generate some buzz. In all cases, however, I think it misses the point. All of these examples simply focus on the word 'augment' and then say 'XXX is augmenting reality'. Semantically, it's hard to argue with. But, practically, if avoids the real issue: what are these different experiences, what do they offer the user (or developer) in terms of capabilities, and are there meaningful differences between them. [...] If everything is AR, then nothing is. [...] So I will keep calling those kinds of experiences (and not other things) AR, until a better collection of definitions is put forth, since my community [academia] has been calling it AR for $>20$ years.

In these responses, we see multiple levels of boundary-work being enacted. There is the appeal to the academic authority and the length of time as further evidence of that authority, while claiming that it is being 'pushed away' from that. Second, specific industry groups are held responsible for this, as academics accuse them as being confused or uninformed of the academic meaning and simply trying to profit off the AR label. Both academic and industry stakeholders worry about the 'public confusion' over AR, but they disagree about the cause of this confusion. Industry actors claim that it is the debate over the AR criteria itself that is confusing (phase 2), whereas the academic community claims that it is the ever expanding list of things that get called AR that is the source of the confusion (phase 3). Third, the definitional question is viewed as existential to the field, where the colloquial definition threatens the entire enterprise.

The most aggressive type of academic boundary work is reserved for industry actors who simply call things AR for marketing purposes to generate hype. Because these companies are proactively trying to claim the authority to define AR through the release of their products, people in the academic community are especially critical of the implications of their definition, their motivations, and their place in the community. They are derided as misinformed, or worse, willfully ignorant. At the two poles of a strict versus broad definition, we can clearly see how the contest over who gets to define the artifact reflects the zero-sum nature of epistemic authority, namely that the "legitimate right to have one's reality claims accepted as valid or marginally useful is no plum at all if everyone enjoys it all the time (Gieryn, 1999, p. 14)."

\subsection{Avoidance of the AR term, Preemptive Definitional Boundaries with Google's Project Glass}


While many industry actors have actively tried to change the meaning of AR through their FCEs or utilize their market authority to simply label their products AR, this is not to say that industry has uniformly chosen to ignore/supplant the academic definition. In fact, there is some evidence that corporate actors are recognizing the controversy across FCEs and choosing to avoid the term altogether. Google's Project Glass was one of the latest artifacts to revive the definitional question, and in April 2012 it was the subject of much speculation as a highly publicized announcement of a large company investing in and testing a commercial head worn device. A number of industry supporters capitalized on the hype at their FCEs, utilizing it as an exemplar for their discussions, presentations, and projections of AR. At AWENY2014 there was a whole session run by a Google Glass community leader called the "Thinking for Google Glass.”

Google themselves, however, never referred to the device as AR, something that was a very selective move on their part. Bill, a researcher who worked on the project, explained: "When I was working at Google we were told not to refer to Glass as augmented reality or an augmented reality device (ISMAR2013)." This illustrates a specific example of how the definitional debate has become so loaded that it is motivating certain companies to move away from the AR label.

Despite the lack of explicit company association, however, many academics in the AR community quickly engaged in definitional boundary work around Project Glass as a preemptive measure and because industry leaders were holding it up as an exemplar. Shortly after Google's announcement, people began to argue that the examples shown through Glass were not AR. Here's an excerpt of a post from Riley, addressing the media, applying some of Azuma's criteria to Glass:

To all the press: this [Glass] is a heads-up display, it's not "augmented reality." AR is about putting content out in the world, virtually attaching it to the objects, people and places around you. You could not do AR with a display like this (the small field of view, and placement off the side, would result in an experience where the content is rarely on the display and hard to discover and interact with), but it's a fine size and structure for a small HUD. The video application concepts are all screen-fixed ("heads up" instead of "in the world") for this reason.

Here we see a reprisal of the interactivity criteria, whether the augmentation needs to be interactive with the object or the user, as well as the implicit 'immersiveness' criteria that was raised about smartphone 
and tablet AR. Since the Project Glass announcement, many people who are engaged in this definitional debate have adopted this boundary perspective. It almost became a rote expression where any reference to Project Glass was followed by the caveat "and I know it's not AR, but..." The Google Glass example is first an example of how the boundary debates across FCEs are observed by and have influence over outside actors, but also indicative of a boundary debate that continues to be enacted around every new device, application, and development in the AR community.

\section{Discussion}

Each of these definitional distinctions, criteria, and permutations therein has their adherents in the broader community (Figure 6). Some are actively antagonistic, like the academic adherents to Azuma and the industry actors who prefer a colloquial definition. All sides have a stake in the meaning of AR, but they believe that the organizing visions, futures, and business problematics accompanying other definitions are either insufficient or actively harming the technology. As new devices and developments continue to emerge, we see a collection of stakeholders that is nominally unified in their support of 'AR' technology, but simmering under the surface are distinct groups that perceive the other as the wrong approach, or worse, an existential threat to their stake in the enterprise. These definitions are deployed to continually challenging which artifacts are 'really AR,' whether they should embrace it, and if not, how they can undermine the actors/definition that are trying to include it (Table 2).

This study first builds on our understanding of the importance of definitions as it relates to larger innovation processes, specifically its role in shaping the organizing visions and membership negotiations that flow from the definition. While the organizing vision framework has built an understanding of how the innovative activities of a wide set of community actors are shaped and sustained by a set of organizing visions (Currie, 2004; Swanson, 2010; Swanson \& Ramiller, 1997), this work further extends that model by examining how a definitional mechanism is intricately linked to organizing visions, and how old and new members alike leverage their power to reshape the community through definitions (table 2). The contestation over definitions contributes to the model by examining a case where groups are not directly competing over organizing visions, rather those narratives are secondary to a contest over definitions 
which shape the spaces where organizing visions circulate. While many existing scholars have explored how certain terms originate and get deployed (Bowker \& Star, 1999; Barrett, Heracleous, \& Walsham, 2013; Pollock \& Williams, 2011; Swanson \& Ramiller, 1997; Wang, 2009), this study explicitly links the definitional debate to the organizing vision framework as a key proxy battle for larger questions of who has authority to shape the technology, the future visions for the technology, and the problems/goals to prioritize. This helps us understand definitions as an important analytical lens for understanding innovation, particularly as a prerequisite for understanding the motivations of various actors and the mechanisms by which organizing vision are produced, through cultural and linguistic resources, interpretive-discursive activities, social structure, and practical activities and objects (Swanson \& Ramiller, 1997).

This study also links the organizing vision framework to the FCEs where these debates are occurring, and in doing so allows us to explicitly map how power and authority play a role in configuring FCEs over a long period of time, as the definitional goals and motivations become material social boundaries. While FCEs are by definition "temporary social organizations" (Lampel \& Meyer, 2008) and recent work has examined the importance of singular FCE at a given moment (Hardy \& Maguire, 2010; Oliver \& Montgomery, 2008), this study builds our understanding of a field that has formed (and diverged) over decades of FCEs. In the earliest phases, the academic FCEs were motivated by a definition of exclusion to clarify independence from other academic fields (Milgram \& Kishino, 1994). Over time they consolidated and strongly coalesced around one definition and its attendant organizing visions (Azuma, 1997), and formalized mechanisms to enforce this structurally through peer review, steering committee membership, and social norms, to create a priori restrictions on who had authority to speak, guide development toward key industry problems, and socialize new members into the definition. While this is consistent with recent work that has examined how hub actors strategically employ definitional control to set core assumptions and include/exclude certain contributions (Prince, Barrett, \& Oborn, 2014), this study builds on that work by explicitly looking at the diverse motivations of various actors as well as highlighting a case of how these definitional boundaries get maintained over time. Through 
recurring FCEs actors were able to structure the FCEs around preexisting sets of assumptions and ideas, and over time it continually narrowed the field and reinforced a stability over these perspectives such that the boundary work to resist alternate definitions and organizing visions was exceptionally strong. This is a good example of why studying FCEs over long periods is important, "as the significance of an event cannot be understood readily in real time, but must be weighed against the overall flow of events over time (Garud, 2008).”

This study also builds on FCEs literature that examines the multiple constructions and narratives that occur within social spaces at a given FCE (Zilber, 2011), but goes further to examine how competing stakeholders can leverage their power to create and solidify their own definitional authority across FCEs. Rather than appeal to the authority of the academic forums, mobile browser companies turned to standards organizations as a place where they could enact their own FCE. While the existing standards literature has focused on the battle over standards and their importance for technological development (Greenstein \& Stango, 2006; Shapiro \& Varian, 1999; Yoffie \& Cusumano, 1998), this study found that standards (and a particular method of standards creation) were being utilized as strategic FCEs to solidify a definition and gain authority.

By turning to a standards consortia as opposed to traditional standards organizations to establish what they named 'Augmented Reality Markup Language (ARML) 2.0,' these mobile browsers were able to 'pay to play,' with membership fees ranging into the tens of thousands depending on the institutional affiliation and level of participation desired. While the OGC is an open consortium, there is a tiered system within that organization where differing levels of membership (and dues) can give actors more voting authority within the organization. Secondary fees also compound this disparity as "the travel and meeting requirements $[\ldots]$ constitute a membership limitation, as very few private citizens have the ability to travel to all of the meetings of an international technical committee where the technology is decided (Cargill \& Bolin, 2007; p. 324).” The market actors, therefore, literally have more monetary power to exert authority in these standards forums to set their definitions. While one of the key characteristics of FCEs scholars highlight is the possibility that minority views could flourish and 
exchange within a given FCE (Hardy \& Maguire, 2010; Oliver \& Montgomery, 2008), here we see an instance where a minority group facing strong boundary work chose not to work within the same FCEs, rather they selected and moved the discussion outside of the academic forums to different FCEs where their resources afforded them more control of definitional forums. By leveraging FCEs that offers tiered access and carries the material power of standards (Bowker \& Star, 1999; Busch, 2011), these moves allowed them to solidify their product as AR while also making the location features and uses of their browsers a standard element in the AR markup language.

Industry AR conferences were another stakeholder group that turned to their own FCEs, which gave them the power to not adhere to the original motivations/constraints of the academic definitions. Beyond using their market authority to simply label call their products AR and create a de facto definition, they invited VR companies to their FCEs (which runs directly counter to the original motivation) and elevated mass market and commercial uses and futures. This practice is codified by inviting market analyst presentations that have a similarly broad definition of AR, a recursive process of field mapping that legitimates the inclusion of self-proclaimed AR companies in the AR space. Building on work that examines how definitions and categorization of technology by industry firms have critical implications for bounding market categories, motivating actors to work in certain areas, and shaping product development (Pollock \& Williams, 2011; Swanson, 2010), this case found that market analysts were furthering the goals of a particular definitional stakeholder group by first accepting a broad definition in how they categorize internally, and then validating that definition through their external reports and authority as market analysts. More broadly, these steps illustrate how minority views at one FCE become a warrant for creating alternate FCEs (with their own authority to invite certain perspectives that align with and enforce their definitions).

While FCEs have been shown to effectively connect individual and organizational actors (Anand \& Watson, 2004; Glynn, 2008) and forge collective beliefs (Zilber, 2007), in this case the actors are not necessarily attempting to span boundaries or come to a mutual understanding about a new artifact (Bechky, 2003; Carlile, 2002) Instead, they are actively disagreeing and contesting definitions, ideas and 
authority. In the first three phases we saw that different FCEs were being created for various definitional/authority reasons. It is in phase four where we see how discourses at these FCEs shift and adjust in relation to one another. Zilber (2011) in particular has called for more work examining the dynamics of FCEs in fields characterized by multiplicity, and this case offers an empirical look at how discourse flows between FCEs and engenders responses across FCEs. The rise of mobile browsers caused some within the academic FCEs to propose broadening the definition, while others hardened in their defense of Azuma by making discursive distinctions between hard/soft AR and placing additional criteria (immersiveness) on these artifacts. The growth of commercial FCEs trying to instantiate a colloquial definition brought about even more rigorous boundary work at academic and standards FCEs, with members suggesting alternate language and criticizing the limitless nature of the colloquial definition. While some have argued that reintroducing smaller spaces with more rigid boundaries outside the larger FCE can yield open and productive spaces where actors can experiment and work with one another (Schüßler, Rüling, \& Wittneben, 2014; Zietsma \& Lawrence, 2010), here we see a case where boundary actors created FCEs around mutually exclusive definitions/visions of the boundary itself.

Across FCEs, actors will attempt to recruit and convert members to their definition, circulate arguments to help their members defend the definition. Within their FCEs, certain stakeholders will respond to events/actions from other FCEs in ways that escalate and further stratify their own definitions to exclude external authority. People even started blaming one another and their definitions for failed market futures, public confusion, and negative public perception of the technology. It is only by situating oneself across FCEs that we can see the multiplicity of these spaces in constructing a field, as well as various alignments and coalitions even as they disagree with one another. For example, the people who advocate strict adherence to Azuma's definition and people who believe mobile browsers should be included may disagree, but they are both united against the colloquial definition. While FCEs can be enacted for many possibilities like field persuasion, sensemaking, and closure (Garud, 2008), this study broadens our understanding of FCEs created explicitly for active contestation and as a direct challenge to the authority (and definitions) of other stakeholders. Boundary work becomes a useful lens for 
understanding these FCEs and discourses across FCEs, as it allows us to first explain the motivations for specific actions and discourse at a given place, but then also to make sense of its presence in relation to actions/discourses at other FCEs.

While this definitional conflict is still ongoing, already we can see instances where the boundary work of various stakeholders had tangible implications for the FCEs as well as the field itself. First lies in the tangible work/outcomes that come out of these FCEs. At the first IWAR in 1999, a panel formed to discuss the possibilities of AR "felt that AR had a great potential in many areas (factories, airplanes, medicine) for trained and untrained users (Fite-Georgel, 2011; p. 201).” A 10 year review of ISMAR found that much of the work has been shaped by this organizing vision was focused on tracking, registration, and calibration (Zhou, Duh, \& Billinghurst, 2008). These organizing visions have also topically focused work at ISMAR on AR medical applications (Bai, Blackwell, \& Coulouris, 2013; Regenbrecht et al., 2011), military maintenance and repair (Henderson \& Feiner, 2009), and other enterprise/business to business problems (Schwerdtfeger \& Klinker, 2008), in an attempt to highlight the utility and necessity of AR (in direct contrast to consumer AR).

Critics, however, have argued that the narrow definition and visions have been limiting development, where a study examining AR applications in enterprise/B2B settings found no projects having moved past the pilot stage into full implementation (Fite-Georgel, 2011). These outcomes have been used by other factions to try to push for changes in how the community conceptualizes the organizing vision, as well as the subsequent invention and adaptation of core technology (Swanson \& Ramiller, 1997). At the standards FCE the mobile AR browsers were focused more on consumer uses of locational AR, and were able to develop and approve ARML 2.0 as an OGC certified technical standard. At the industry conferences, their focus on mass market and consumer use gave rise to a surge in AR marketing applications and advertising partnerships that dominate the AR space (Liao, 2015). These outcomes and developments are empirical examples of how futures and organizing visions do actively shape development (Brown, Rapper, \& Webster, 2000; Borup et al., 2006; Swanson \& Ramiller, 1997). 
The second outcome of the definitional boundary work is the power it has over what products get called 'AR'. While the academic community can enforce both symbolic and social boundaries in the work evaluation processes within their own forums (Lamont \& Molnar, 2002), they have less power over the industry conferences, industry analysts, and cannot directly influence the decisions of the companies/analysts. Their optimal scenario may be what happened with Google Glass, where their symbolic definitional boundary raised the perceived costs of using the term AR to the point where it deterred an industry giant from traversing into that boundary. While existing research has identified cycles of boundary work amongst insiders/outsiders (Zietsma \& Lawrence, 2010), this case illustrates how merely the presence/politicization of these boundary spaces between actors can have their own power. With the case of Google Glass, the boundary dispute moves across these FCE as stakeholders assert their symbolic and social authority beyond their own FCE by turning to public media outlets or trade groups to broaden the reach of their boundary. These subsequently affect decisions over what to label real products, which ultimately have implications for the public's understanding of the technology and associations with the technology.

\section{Conclusion}

As emerging digital technologies often bring together and reconfigure disparate domains of expertise and authority, they become important places for organizational researchers to examine the process of innovation (Yoo et al., 2012). AR technologies in particular are an important new area for organizational research, given that there are a variety of promises being made about them and their ability to display and aggregate data, visualize 3-D content, and enhance human visual capacity (Liao, 2012). Many applications are currently being developed and being considered for companies, ranging from helping stockroom workers find and place inventory to helping surgeons perform highly complex medical operations. Other AR applications are currently being piloted for shipping companies to check deliveries, and to help maintenance employees fix machinery. While future work might seek to understand how these technologies are adopted by the specific organizations, how they gain meaning and restructure work practices within an organization, and are ultimately appropriated or rejected by members of the 
organization (see Barrett, Oborn, Orlikowski, \& Yates, 2012; Orlikowski, 2000; Zuboff, 1988), this study helps explain the period of intense negotiation amongst the creators of the technology over the design, business problematics, practitioner culture, and essential problems to tackle which might one day lead to that adoption.

For many emerging technologies where the field is still being determined, this case shows how the agreed upon definitions are simultaneously the motivation, unification, and legitimation of the community. Where different actors attempt to contest or enforce the definition, they are attempting to reconstitute the field in a specific form. The physical places where these debates happen also provide evidence of the differences between definitions, the underlying motivation behind certain definitions, the methods for where they contest organizational authority and visions, and the implications behind those moves. Understanding the construction of and power of these boundaries and their relationship to temporal FCEs is an important step to understanding the field level dynamics that construct emerging technologies.

\section{Acknowledgements}

This article was supported by grants from the National Science Foundation Science Technology and Society Division [Award \#1330297] and Cornell's Institute for the Social Sciences.

\section{References}

Abbate, J. (2000). Inventing the internet. MIT press.

Anand, N., \& Watson, M. R. (2004). Tournament rituals in the evolution of fields: The case of the Grammy Awards. Academy of Management journal,47(1), 59-80.

Azuma, R. T. (1997). A survey of augmented reality. Presence, 6(4), 355-385.

Bai, Z., Blackwell, A., \& Coulouris, G. (2013, October). Through the looking glass: Pretend play for children with autism. In Mixed and Augmented Reality (ISMAR), 2013 IEEE International Symposium on (pp. 49-58). IEEE.

Barrett, M., Heracleous, L., \& Walsham, G. (2013). A rhetorical approach to IT diffusion: Reconceptualizing the ideology-framing relationship in computerization movements. MIS Quarterly, 37(1), 201-220.

Barrett, M., Oborn, E., Orlikowski, W. J., \& Yates, J. (2012). Reconfiguring boundary relations: Robotic innovations in pharmacy work. Organization Science, 23(5), 1448-1466. doi: 10.1287/orsc. 1100.0639

Bazerman, C. (1999). The languages of Edison's light (p. 53). Cambridge: MIT press.

Bechky, B. A. (2003). Sharing meaning across occupational communities: The transformation of understanding on a production floor. Organization science, 14(3), 312-330.

Berlin, L. (2009). Kicking reality up a notch. New York Times. Retrieved from 
http://www.nytimes.com/2009/07/12/business/12proto.html? r=2\&scp=15\&sq=Sportvision\&st=c se\&

Bijker, W. E. (1995). Of bicycles, bakelites, and bulbs: Toward a theory of sociotechnical change. MIT press.

Borup, M., Brown, N., Konrad, K., \& Van Lente, H. (2006). The sociology of expectations in science and technology. Technology analysis \& strategic management, 18(3-4), 285-298. doi: 10.1080/09537320600777002

Bowker, G. C., \& Star, S. L. (1999). Sorting things out: Classification and its consequences. MIT press.

Brown, N., Rappert, B., \& Webster, A. (Eds.). (2000). Contested futures: A sociology of prospective techno-science. Aldershot: Ashgate.

Busch, L. (2011). Standards: Recipes for reality. Mit Press.

Callon, M. (1986). Some elements of a sociology of translation: domestication of the scallops and the fishermen of St. Brieuc Bay. Power, action, and belief: A new sociology of knowledge, 32, 196223.

Cargill, C., \& Bolin, S. (2007). Standardization: a failing paradigm. Standards and public policy, 296328.

Carlile, P. R. (2002). A pragmatic view of knowledge and boundaries: Boundary objects in new product development. Organization science, 13(4), 442-455.

Caudell, T. P., \& Mizell, D. W. (1992, January). Augmented reality: An application of heads-up display technology to manual manufacturing processes. In System Sciences, 1992. Proceedings of the Twenty-Fifth Hawaii International Conference on (Vol. 2, pp. 659-669). IEEE.

Currie, W. L. (2004). The organizing vision of application service provision: a processoriented analysis. Information and Organization, 14(4), 237-267. doi: 10.1016/j.infoandorg.2004.07.001

Emerson, R. M., Fretz, R. I., \& Shaw, L. L. (2011). Writing ethnographic fieldnotes. University of Chicago Press.

Fite-Georgel, P. (2011, October). Is there a reality in Industrial Augmented Reality?. In Mixed and Augmented Reality (ISMAR), 2011 10th IEEE International Symposium on (pp. 201-210). IEEE.

Flichy, P. (2007). Understanding technological innovation: a socio-technical approach. Edward Elgar Publishing.

Fortun, M. (2008). Promising genomics: Iceland and deCODE genetics in a world of speculation. Univ of California Press.

Freeman, C., \& Soete, L. (Eds.). (1997). The economics of industrial innovation. Psychology Press.

Gieryn, T. F. (1983). Boundary-work and the demarcation of science from non-science:

Strains and interests in professional ideologies of scientists. American sociological review, 781795. doi: $10.2307 / 2095325$

Gieryn, T. F. (1999). Cultural boundaries of science: Credibility on the line. University of Chicago Press.

Glynn, M. A. (2008). Configuring the field of play: How hosting the Olympic Games impacts civic community. Journal of Management Studies, 45(6), 1117-1146.

Greenstein, S., \& Stango, V. (Eds.). (2006). Standards and public policy. Cambridge University Press.

Grint, K., \& Willcocks, L. (1995). Business process re-engineering in theory and practice: business paradise regained?. New Technology, Work and Employment, 10(2), 99-109. doi: $10.1111 / \mathrm{j} .1468-005 X .1995 . t b 00009 . \mathrm{x}$

Hardy, C., \& Maguire, S. (2010). Discourse, field-configuring events, and change in organizations and institutional fields: Narratives of DDT and the Stockholm Convention. Academy of Management Journal, 53(6), 1365-1392.

Hedgecoe, A., \& Martin, P. (2003). The Drugs Don't Work Expectations and the Shaping 
of Pharmacogenetics. Social Studies of Science, 33(3), 327-364. doi: 10.1177/03063127030333002

Henderson, S. J., \& Feiner, S. (2009, October). Evaluating the benefits of augmented reality for task localization in maintenance of an armored personnel carrier turret. In Mixed and Augmented Reality, 2009. ISMAR 2009. 8th IEEE International Symposium on (pp. 135-144). IEEE.

Garud, R. (2008). Conferences as venues for the configuration of emerging organizational fields: The case of cochlear implants. Journal of Management Studies, 45(6), 1061-1088.

Lamont, M. (1992). Cultivating differences: Symbolic boundaries and the making of inequality. University of Chicago Press.

Lamont, M., \& Molnár, V. (2002). The study of boundaries in the social sciences. Annual review of sociology, 167-195.

Lampel, J., \& Meyer, A. D. (2008). Guest editors' introduction: Field-configuring events as structuring mechanisms: How conferences, ceremonies, and trade shows constitute new technologies, industries, and markets. Journal of Management Studies, 45(6), 1025-1035.

Liao, T. (2012, November). A framework for debating augmented futures: Classifying the visions, promises and ideographs advanced about augmented reality. In Mixed and Augmented Reality (ISMAR-AMH), 2012 IEEE International Symposium on (pp. 3-12). IEEE.

Liao, T. (2015). Augmented or admented reality? The influence of marketing on augmented reality technologies. Information, Communication \& Society, 18(3). doi: 10.1080/1369118X.2014.989252

Liao, T., \& Humphreys, L. (2014). Layar-ed places: Using mobile augmented reality to tactically reengage, reproduce, and reappropriate public space. New Media \& Society, 1461444814527734.

Lofland, J., Snow, D., Anderson, L., \& Lofland, L.H. (2006). Analyzing social settings: A guide to qualitative observation and analysis. Belmont, CA: Wadsworth.

Marvin, C. (1988). When old technologies were new. Oxford University Press.

McInerney, P. B. (2008). Showdown at Kykuit: Field-configuring events as loci for conventionalizing accounts. Journal of Management Studies, 45(6), 1089-1116.

Meyer, A. D., Gaba, V., \& Colwell, K. A. (2005). Organizing far from equilibrium: Nonlinear change in organizational fields. Organization Science, 16(5), 456-473.

Milgram, P., \& Kishino, F. (1994). A taxonomy of mixed reality visual displays.IEICE TRANSACTIONS on Information and Systems, 77(12), 1321-1329.

Oliver, A. L., \& Montgomery, K. (2008). Using field-configuring events for sense-making: a cognitive network approach. Journal of Management Studies, 45(6), 1147-1167.

Orlikowski, W. J. (2000). Using technology and constituting structures: A practice lens for studying technology in organizations. Organization science,11(4), 404-428. doi: 10.1287/orsc.11.4.404.14600

Pavlik, J. V., \& Bridges, F. (2013). The emergence of augmented reality (AR) as a storytelling medium in journalism. Journalism \& Communication Monographs, 15(1), 4-59. doi: $\underline{10.1177 / 1522637912470819}$

Pollock, N., \& Williams, R. (2010). The business of expectations: How promissory organizations shape technology \& innovation. Social Studies of Science. doi: $\underline{10.1177 / 0306312710362275}$

Pollock, N., \& Williams, R. (2011). Who decides the shape of product markets? The knowledge institutions that name and categorise new technologies. Information and Organization, 21(4), 194-217. doi: 10.1016/j.infoandorg.2011.08.001

Prince, K., Barrett, M., \& Oborn, E. (2014). Dialogical strategies for orchestrating strategic innovation networks: the case of the Internet of Things. Information and Organization, 24(2), 106-127.

Ramiller, N. C., \& Swanson, E. B. (2003). Organizing visions for information technology and the information systems executive response. Journal of Management Information Systems, 20(1), 13-50. 
Regenbrecht, H., McGregor, G., Ott, C., Hoermann, S., Schubert, T., Hale, L., ... \& Franz, E. (2011, October). Out of reach?-A novel AR interface approach for motor rehabilitation. In Mixed and Augmented Reality (ISMAR), 2011 10th IEEE International Symposium on (pp. 219-228). IEEE.

Schwerdtfeger, B., \& Klinker, G. (2008, September). Supporting order picking with augmented reality. In Proceedings of the 7th IEEE/ACM international Symposium on Mixed and Augmented Reality (pp. 91-94). IEEE Computer Society.

Schüssler, E., Rüling, C. C., \& Wittneben, B. B. (2014). On melting summits: The limitations of fieldconfiguring events as catalysts of change in transnational climate policy. Academy of Management Journal, 57(1), 140-171.

Sielhorst, T., Feuerstein, M., \& Navab, N. (2008). Advanced medical displays: A literature review of augmented reality. Display Technology, Journal of, 4(4), 451-467. doi: 10.1109/JDT.2008.2001575

Shapiro, C., \& Varian, H. R. (1999). The art of standards wars. Managing in the modular age, 247-272.

Star, S. L., \& Griesemer, J. R. (1989). Institutional ecology translations' and boundary objects: Amateurs and professionals in Berkeley's Museum of Vertebrate Zoology, 190739. Social studies of science, 19(3), 387-420. doi: 10.1177/030631289019003001

Swanson, E. B. (2010). Consultancies and capabilities in innovating with IT.The Journal of Strategic Information Systems, 19(1), 17-27. doi: 10.1016/j.jsis.2009.12.001

Swanson, E. B., \& Ramiller, N. C. (1997). The organizing vision in information systems innovation. Organization science, 8(5), 458-474. doi: 10.1287/orsc.8.5.458

Swanson, E. B., \& Ramiller, N. C. (2004). Innovating mindfully with information technology. MIS quarterly, 553-583.

Suddaby, R., \& Greenwood, R. (2001). Colonizing knowledge: Commodification as a dynamic of jurisdictional expansion in professional service firms. Human relations, 54(7), 933953. doi: $10.1177 / 0018726701547007$

Wang, P. (2008). Whatever happened to business process reengineering? The rise, fall, and possible retrieval of business process reengineering: From the organizing vision perspective. in Business Process Transformation, V. Grover and M.L. Markus (eds.), Armonk, NY: M.E. Sharpe. 23-40.

Wang, P. (2009). Popular concepts beyond organizations: Exploring new dimensions of information technology innovations. Journal of the Association for Information Systems, 10(1), 130.

Wyatt, S. (2004). Danger! Metaphors at work in economics, geophysiology, and the Internet. Science, Technology \& Human Values, 29(2), 242-261.

Van Krevelen, D. W. F., \& Poelman, R. (2010). A survey of augmented reality technologies, applications and limitations. International Journal of Virtual Reality, 9(2), 1.

Van Lente, H., \& Rip, A. (1998). The rise of membrane technology from Rhetorics to social reality. Social studies of science, 28(2), 221-254. doi: 10.1177/030631298028002002

Yoffie, D. B., \& Cusumano, M. A. (1998). Competing on internet time: Lessons from netscape and its battle with microsoft. Simon and Schuster.

Yoo, Y., Boland Jr, R. J., Lyytinen, K., \& Majchrzak, A. (2012). Organizing for innovation in the digitized world. Organization Science, 23(5), 1398-1408. doi: $\underline{10.1287 / \text { orsc. } 1120.0771}$

Zhou, F., Duh, H. B. L., \& Billinghurst, M. (2008, September). Trends in augmented reality tracking, interaction and display: A review of ten years of ISMAR. In Proceedings of the 7th IEEE/ACM International Symposium on Mixed and Augmented Reality (pp. 193-202). IEEE Computer Society.

Zietsma, C., \& Lawrence, T. B. (2010). Institutional work in the transformation of an organizational field: The interplay of boundary work and practice work. Administrative Science Quarterly, 55(2), 189221.

Zilber, T. B. (2007). Stories and the discursive dynamics of institutional entrepreneurship: The case of Israeli high-tech after the bubble. Organization Studies, 28(7), 1035-1054. 
Zilber, T. B. (2011). Institutional multiplicity in practice: A tale of two high-tech conferences in Israel. Organization Science, 22(6), 1539-1559.

Zuboff, S. (1988). In the age of the smart machine: The future of work and power. Basic Books. 
Table 1. Interview Participants and Descriptions

\begin{tabular}{|c|c|c|}
\hline .Pseudonym & Professional Description & Affiliation \\
\hline Bran & Lawyer Specializing in Emerging Technologies & Industry \\
\hline Karl & Director of Computer Vision for AR Hardware Company & Industry \\
\hline Will & Chief Financial Officer of AR Company & Industry \\
\hline Adam & Founder of AR Consulting Firm and Blog & Industry \\
\hline Ramsey & Police Chief Specializing in Cybercrime & Industry \\
\hline Walter & CEO of a AR Software Company & Industry \\
\hline Santos & Founder of AR Media Website & Industry \\
\hline Linus & CEO of AR Software Company & Industry \\
\hline Aaron & $\begin{array}{l}\text { Founder of AugmentedReality.Org, Co-organizer of ARE, } \\
\text { AWE, ARNY }\end{array}$ & Industry \\
\hline Rodney & Programmer at AR Software Company & Industry \\
\hline Fred & Professor of Computer Science in U.S. & Academia \\
\hline Dennis & Ph.D Student of Computer Science in U.S. & Academia \\
\hline Luke & Ph.D Student of Computer Science in Singapore & Academia \\
\hline Mary & User Experience Researcher in Portugal & Academia \\
\hline Arthur & Professor and Software Engineer in U.K & Academia \\
\hline Stan & $\begin{array}{l}\text { ISMAR Steering Committee Member, Director of AR } \\
\text { Laboratory in U.S. }\end{array}$ & Academia \\
\hline Carla & Director of R+D for Location-Based Mapping Company & Industry \\
\hline Giovanni & Post-Doctoral Researcher in Computer Science in the UK & Academia \\
\hline Seth & ISMAR Steering Committee Member & Academia \\
\hline Liu & $\begin{array}{l}\text { ISMAR Steering Committee Member, Professor of Computer } \\
\text { Science in New Zealand }\end{array}$ & Academia \\
\hline Brian & Professor of Computer Science in U.S. & Academia \\
\hline Greta & $\begin{array}{l}\text { Former ISMAR Program Chair, Professor of English at } \\
\text { University in Sweden }\end{array}$ & Academia \\
\hline Colleen & Co-Director of AR Laboratory in the Netherlands & Academia \\
\hline Victor & Co-Director of AR Laboratory in the Netherlands & Academia \\
\hline Nathan & Ph.D in Digital Media in the United States & Academia \\
\hline Nick & $\begin{array}{l}\text { Technical Director of a Computer Software Company in the } \\
\text { UK }\end{array}$ & Industry \\
\hline Percy & Chief Engineer for a Standards Setting Organization & Standards \\
\hline Lester & Chief Technical Officer for an AR Software Company & Industry \\
\hline Boris & Head of an AR Standards Development Group & Standards \\
\hline Richard & President of a Standards Setting Organization & Standards \\
\hline Simon & Participant in the ARML Standards Process & Standards \\
\hline Evan & Participant in the ARML Standards Process & Standards \\
\hline Tina & Founder of International AR Standards Community & Standards \\
\hline Hillis & CEO of AR Application Company & Industry \\
\hline Ray & CEO of Construction Company adopting AR & Industry \\
\hline Terry & Consultant for AR Company & Industry \\
\hline Morton & CTO of AR Sports Company & Industry \\
\hline Gerald & Co-Founder of AR Software Company & Industry \\
\hline Morris & CEO of AR Computer Vision Company & Industry \\
\hline Dmitry & CEO of AR Navigation Company & Industry \\
\hline Josephine & Marketing Director for AR Software Company & Industry \\
\hline
\end{tabular}




\begin{tabular}{|ll|l|}
\hline Murray & CEO of AR Hardware Company & Industry \\
\hline Rick & CEO of AR Creative Agency & Industry \\
\hline Ashton & Project Manager of a Computer Vision Company & Industry \\
\hline Sven & Digital Technology Artist & Academia \\
\hline Justin & Analyst for a Marketing Research Company & Industry \\
\hline Peter & CEO of an AR Software Company & Industry \\
\hline Riley & Professor of Computer Science in U.S. & Academia \\
\hline
\end{tabular}

Table 2. Definitional Motivations, Enactments, and Arguments

\begin{tabular}{|c|c|c|c|c|}
\hline Definition & $\begin{array}{l}\text { Original } \\
\text { Motivation }\end{array}$ & $\begin{array}{l}\text { Definitional } \\
\text { Enactment at } \\
\text { FCE }\end{array}$ & Proponents Argue & Critics Argue \\
\hline $\begin{array}{l}\text { Milgram and } \\
\text { Kishino, } \\
1994 \\
\end{array}$ & $\begin{array}{l}\text { Independence } \\
\text { from VR }\end{array}$ & $\begin{array}{l}\text { Peer Review at } \\
\text { ISMAR, Social } \\
\text { Norms }\end{array}$ & $\begin{array}{l}\text { Distinguishing from } \\
\text { VR is a necessary } \\
\text { baseline }\end{array}$ & $\begin{array}{l}\text { Definition lacks } \\
\text { clear criteria for } \\
\text { what constitutes } \\
\text { AR }\end{array}$ \\
\hline Azuma, 1997 & $\begin{array}{l}\text { Establishment } \\
\text { of AR as } \\
\text { Academic } \\
\text { Field }\end{array}$ & $\begin{array}{l}\text { Peer Review at } \\
\text { ISMAR, Steering } \\
\text { Committee } \\
\text { Membership, } \\
\text { Social Norms } \\
\end{array}$ & $\begin{array}{l}\text { Criteria is necessary } \\
\text { to bound the field } \\
\text { and focus } \\
\text { development }\end{array}$ & $\begin{array}{l}\text { Criteria are up for } \\
\text { dispute, could } \\
\text { arbitrarily exclude } \\
\text { relevant work, } \\
\text { focuses on the } \\
\text { technology not the } \\
\text { user }\end{array}$ \\
\hline $\begin{array}{l}\text { Mobile } \\
\text { Locational } \\
\text { AR }\end{array}$ & $\begin{array}{l}\text { Embracing } \\
\text { corporate } \\
\text { mobile } \\
\text { developments }\end{array}$ & $\begin{array}{l}\text { Defining Terms in } \\
\text { a Formal Standard, } \\
\text { Voting Rights } \\
\text { within Standards } \\
\text { Consortia, } \\
\text { Formally } \\
\text { Approving a } \\
\text { Standard Markup } \\
\text { Language }\end{array}$ & $\begin{array}{l}\text { Real-world } \\
\text { developments } \\
\text { justifies a revisiting } \\
\text { of old definition }\end{array}$ & $\begin{array}{l}\text { Broadens focus to } \\
\text { commercial uses } \\
\text { that are mundane, } \\
\text { overemphasizes } \\
\text { locational uses }\end{array}$ \\
\hline Colloquial & $\begin{array}{l}\text { Branding } \\
\text { corporate } \\
\text { products as } \\
\text { AR }\end{array}$ & $\begin{array}{l}\text { Industry Labelling, } \\
\text { Inviting VR } \\
\text { Companies to } \\
\text { Conferences, } \\
\text { Market Analyst } \\
\text { Firms }\end{array}$ & $\begin{array}{l}\text { Academic definition } \\
\text { is confusing, term } \\
\text { should be used as } \\
\text { marketing label and } \\
\text { focus on users }\end{array}$ & $\begin{array}{l}\text { Lacks any } \\
\text { boundaries at all, } \\
\text { could confuse } \\
\text { users, could cause } \\
\text { subpar products to } \\
\text { be associated with } \\
\text { AR }\end{array}$ \\
\hline Hard/Soft & $\begin{array}{l}\text { Preserving } \\
\text { hierarchy of } \\
\text { AR }\end{array}$ & Social & $\begin{array}{l}\text { Certain AR } \\
\text { problems have not } \\
\text { been solved that are } \\
\text { important, shouldn't } \\
\text { let possibility mobile } \\
\text { detract from or close } \\
\text { off development }\end{array}$ & $\begin{array}{l}\text { Proof of academic } \\
\text { elitism/machismo, } \\
\text { dismisses } \\
\text { important } \\
\text { developments, } \\
\text { preserves a highly } \\
\text { narrow focus }\end{array}$ \\
\hline
\end{tabular}


Fig 1. Institutional production of organizing visions (Adapted from Swanson \& Ramiller, 1997, p. 462)

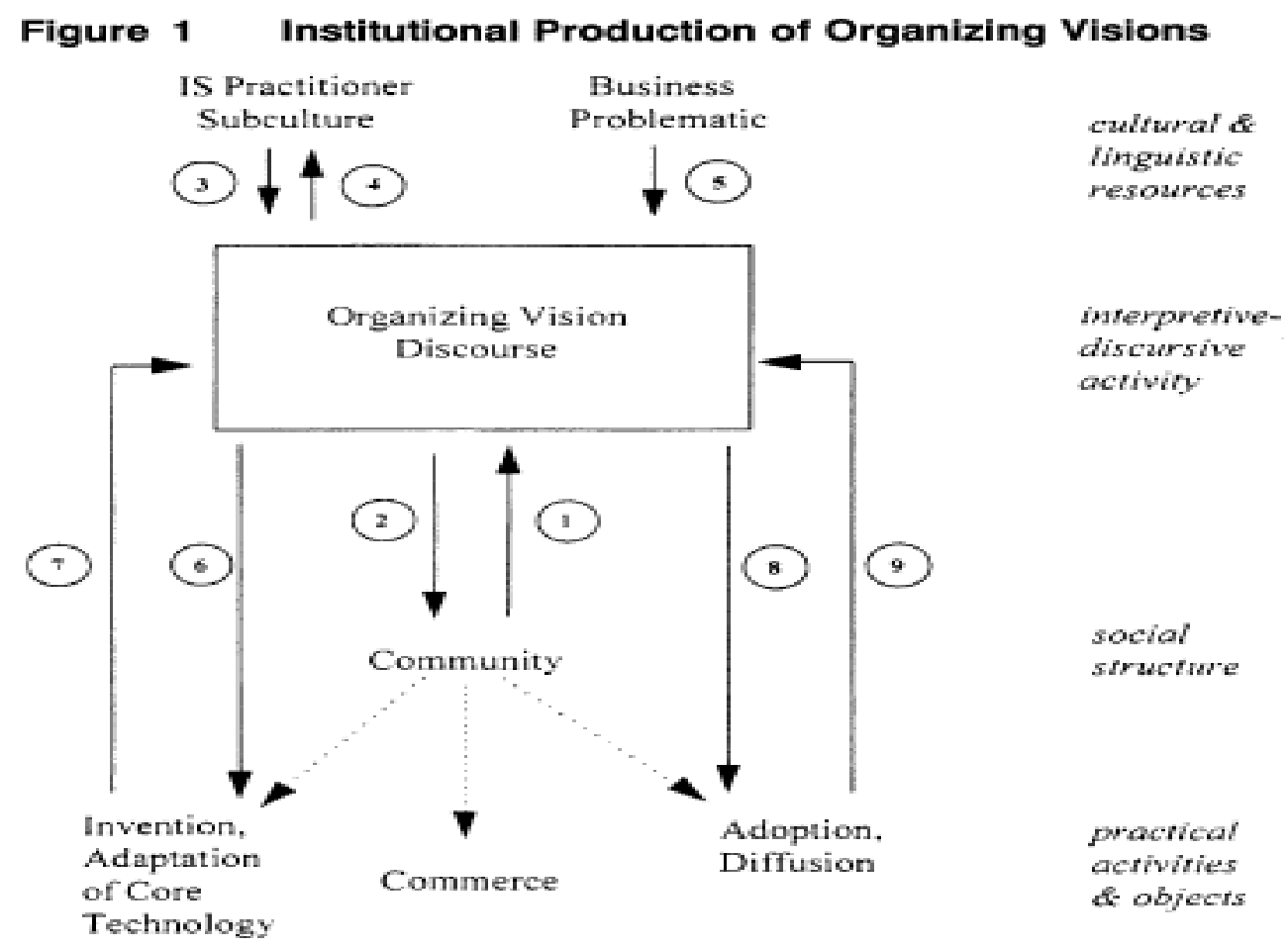

Fig. 2 - Mixed Reality Spectrum, from Milgram \& Kishino, 1994

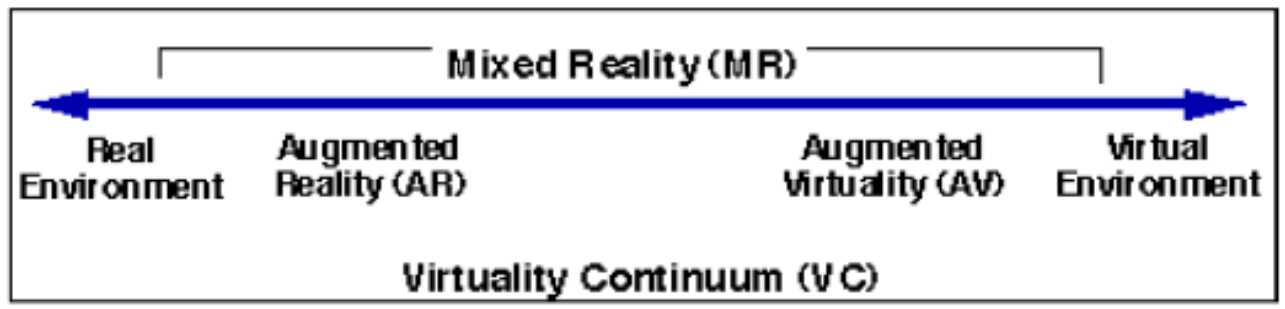

Fig. $3-1^{\text {st }}$ and Ten, Sportvision

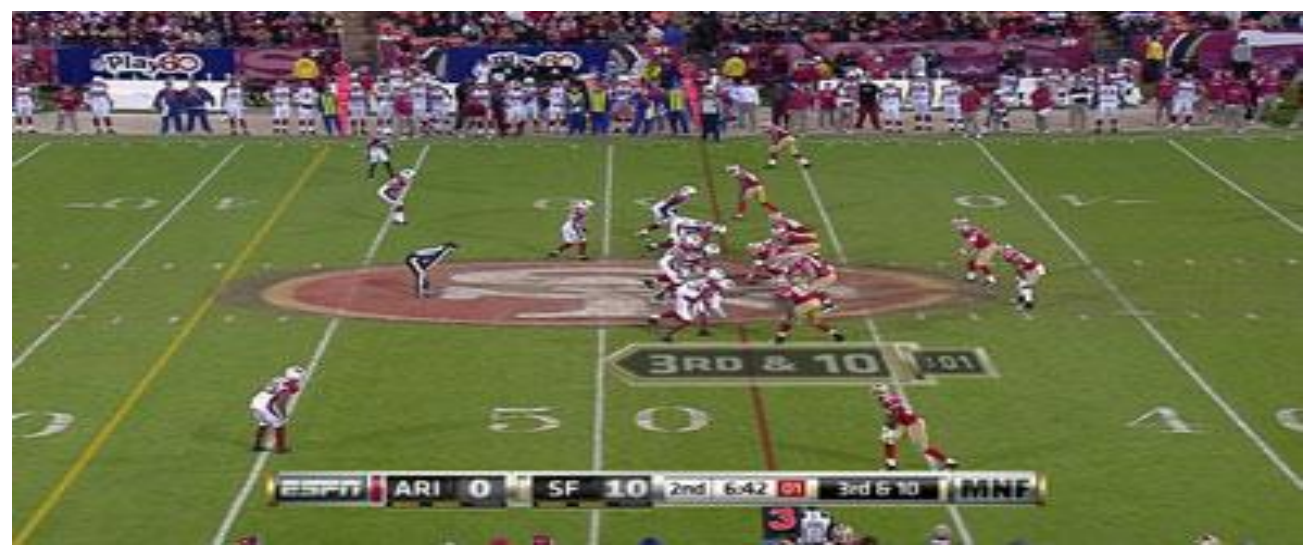


Fig. 4 - User Centric Requirement for Interactivity, Created by Author

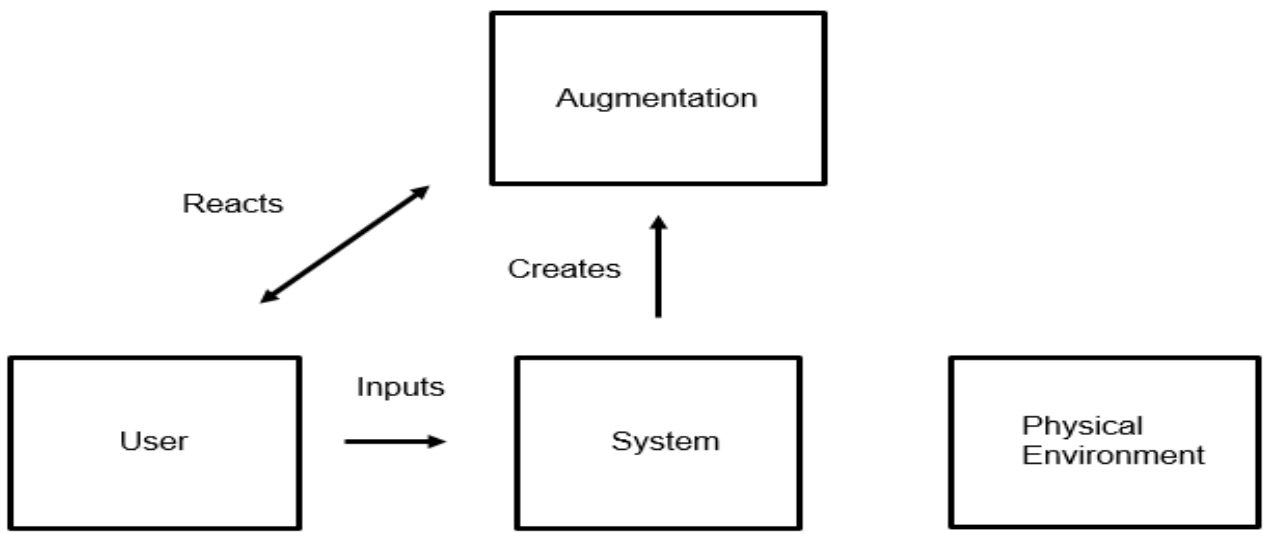

Fig. 5 - System Centric Requirement for Interactivity, Created by Author

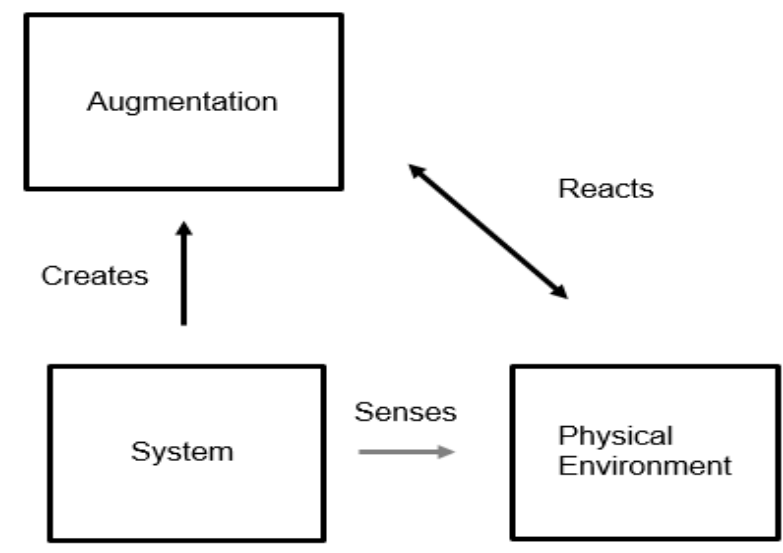

Fig.6 - Spatial Map of Criteria and Definitions - Image by Author

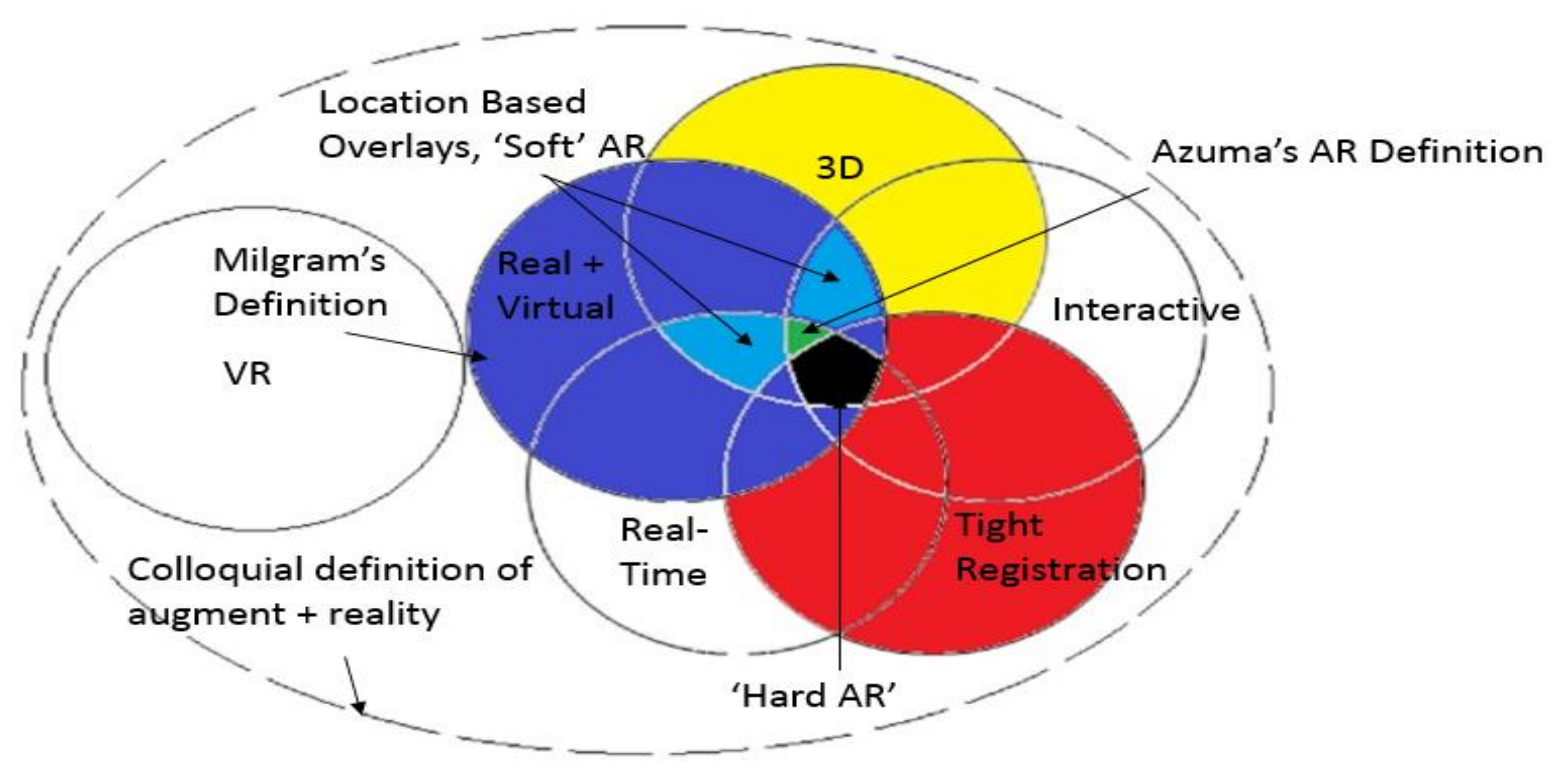

